\section{Mind the gap! A comparison of oral health knowledge between dental, healthcare professionals and the public}

\author{
W. Richards, ${ }^{* 1}$ T. Filipponi ${ }^{1}$ and V. Roberts-Burt ${ }^{1}$
}

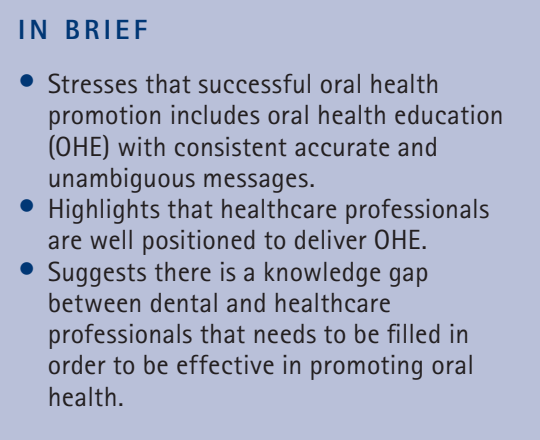

Introduction The importance of consistent, accurate and unambiguous messages are well documented in oral health promotion literature. Whether the reality of delivering messages in the field fulfils these principle is questionable. Objective This paper explores the perceptions of dental professionals, healthcare professionals and lay community members with regard to key oral health messages in order to highlight any inconsistencies and knowledge gaps between and within groups for disease risk factors. Method A questionnaire was administered to individuals who belonged to three groups: dental professionals, healthcare professionals and lay community members. The questionnaire established knowledge regarding risk factors for caries, periodontal disease and erosion. Results Thirty-five (57.4\%) of the dental group answered the whole questionnaire correctly, with $22(27.8 \%)$ and $9(5.1 \%)$ of the healthcare and lay community group answering the whole questionnaire correctly, respectively. The question of fluoride levels in children's toothpaste was the main reason for incorrect answers in the dental group. Conclusions The results of this survey demonstrate a knowledge gradient from dental professionals through to healthcare professionals and then to lay members of the community. The knowledge base observed in the dental group is reflected in the other two groups as would be expected albeit with a significant gap between each group. As expected the dental professionals are generally well informed, but not as well informed as could be expected.

\section{INTRODUCTION}

Caries, periodontal disease and erosion are common dental diseases that are, in the main, preventable. ${ }^{1}$ However, the prevalence of these diseases remains substantial within communities in the United Kingdom. ${ }^{2}$ This is particularly so for deprived population sub-groups. ${ }^{3}$ Furthermore, the disparities in disease prevalence between high and low socioeconomic groups are increasing. ${ }^{4-6}$ The determinants of oral health have been identified as deprivation, age, gender, ethnicity, environment, psycho-social, poverty and lifestyle. ${ }^{4}$

Attempts to improve oral health through oral health promotion (OHP) activities have increased inequalities. ${ }^{7-9}$ Also attempts to address the oral health behaviours of individuals within the community by dental professionals have resulted in negative opinions following unsuccessful interactions. ${ }^{10}$ Perceptions may then develop

\footnotetext{
${ }^{1}$ Faculty of Health Sport and Science, University of South Wales, Pontypridd, CF37 1DL

${ }^{*}$ Correspondence to: Wayne Richards

Email:wayne.richards@southwales.ac.uk
}

Online article number E7

Refereed Paper - accepted 11 December 2013

DOI: 10.1038/sj.bdj.2014.100

${ }^{\circ}$ British Dental Journal 2014; 216: E7 that behavioural limitations have to be tolerated in labelled sub-groups and thus strategies that do not depend on individual behaviour are prioritised and promoted by the dental establishment in order to improve population oral health.

Public health strategies to address caries levels in the community have been delivered on a collective population basis with water fluoridation being high on the agenda as this approach impacts on disease levels regardless of the individual's behaviour. ${ }^{1}$ The distribution of caries in the community remains the same utilising a water fluoridation approach, with deprived subgroups experiencing most of the disease. ${ }^{11}$ Batchelor, ${ }^{12}$ in the context of population oral health, highlights the fact that: "the likelihood of increasing inequalities in health with a population approach was dependent upon whether the strategy was structural, that is, targets conditions in which behaviour occurs, or agentic, in which the target is behaviour change among individuals. Where the intervention is the latter, that is, is dependent on individuals' ability to act, such approaches are likely to increase inequities. They also highlight that for a programme to be targeted at 'those in need' that the cut-off point has to be defined and that this would at some level be somewhat arbitrary; the group would be different from the rest of society. This is likely to stigmatise what is already almost certainly a marginalised group. In certain circumstances, some targeted interventions may be appropriate, for example those who use injection drugs or sex trade workers. Managing carious lesions calls for both collective population and individual behavioural approaches in order to improve population oral health. ${ }^{13}$ Hong et al. conclude that current preventive methods to reduce caries in water fluoridated areas may have reached their maximum effectiveness and behavioural approaches focusing on habits need to be addressed. ${ }^{14}$

With regard to periodontal disease and erosion, behavioural approaches are essential in order to address these conditions within communities. There is an observed social gradient for periodontal conditions. ${ }^{15-17}$ The literature surrounding erosion is conflicting; some investigations showed a significant positive relationship between tooth erosion experience and socioeconomically deprived areas, ${ }^{18-20}$ other studies have observed more erosive lesions in children from higher socioeconomic groups. ${ }^{21-26}$

Shah et al. suggest that interventions to change behaviour have enormous potential to 
alter disease patterns in a positive direction, in the context of unifying the oral health education (OHE) message. ${ }^{27}$ Inconsistencies are found in message content and delivery between healthcare professionals and also within dental professionals. ${ }^{27,28}$

Stillman-Lowe ${ }^{29}$ questions what lessons have been learned from oral health education. In her paper she identifies four issues that could be addressed to improve effectiveness for the future, which include: consideration to community versus individual targeted approach; unambiguous messages delivered in a uniform manner; accuracy of messages for example, fluoride levels in toothpastes for children; specific rather than general messages, highlighting that the general message of 'eat less sweets' is unhelpful.

This paper explores the perceptions of dental professionals, healthcare professionals and lay community members with regard to key oral health messages in order to highlight any inconsistencies and knowledge gaps between and within groups for disease risk factors.

\section{METHODS}

A questionnaire used in a previous study by Aggarwal et al., ${ }^{30}$ constructed specifically for a similar investigation, was identified as the ideal tool to gather relevant data. The questionnaire had been piloted for readability, relevance of questions and ease of use among dental professionals, but had not been tested with other groups; therefore a pilot of the questionnaire was undertaken to obtain feedback on the terminology. As positive feedback was received by lay community members no changes were made to the format.

The questionnaire included demographical questions on gender, age, professional role and years of professional practice for dental and health carers. The general public questionnaire included questions on gender, age and frequency of dental visits. The second part of the questionnaire included nine true/false/don't know questions on key preventive oral health messages on the most common dental diseases: caries, periodontal disease and erosion (Fig. 1). The statements were divided into three categories: caries prevention $(n=4)$, periodontal disease prevention $(n=4)$ and erosion prevention $(\mathrm{n}=1)$.

The professional disciplines included: dentists, orthodontists, hygienists, dental nurses, public health dietitians, general medical practitioners, pharmacists, health visitors and specialist and general nurses. The dental professionals were recruited from professional group meetings and individuals from dental practices. The pharmacists, general medical practitioners and public health dietitians were recruited in the same way. The other health professionals were recruited from the University of South Wales as they attended further and higher education courses.

The geographic location for the recruitment of the community members was primarily within specific areas of Merthyr Tydfil, Pontypridd, Caerphilly and Cardiff, in South Wales. These particular locations were chosen because of their socioeconomic standing as being the least affluent areas based on post code information provided by the Welsh Index of Multiple Deprivation (WIMD, 2011) on the Welsh Government website. ${ }^{31}$ Such areas are believed to have significant numbers of individuals with lower standards of general education ranging from no formal qualifications to a minority reaching levels of a higher diploma, national vocational qualifications (NVQs) or business and technology education council (BTEC) qualifications. Furthermore, these areas show worse health and health indicators and a higher level of unemployment. ${ }^{32}$ The participants were recruited from regular meetings of community groups, congregational event arenas such as leisure centres and other community and social type gatherings.

Ethical approval from the Faculty of Health, Sport and Science's Ethics Committee of the University of South Wales was granted before any data collection took place. Participants were briefed on the purpose of the research and consent forms were completed following questions from participants regarding the survey. Data were anonymously collected and analysed as participants were not requested to provide their names or any other information that could be used to identify them in person.

Data from the respondents were used to assess whether there were differences in knowledge by each group surveyed. Data were also analysed by types of dental diseases. The effect of professional experience and service utilisation by patients were investigated. Data were entered into SPSS (Statistics 20) and results were analysed using Chi-square tests.

\section{RESULTS}

\section{Response rates}

The survey returned 315 completed questionnaires with a response rate of $100 \%$. The participants consisted of 4 orthodontists, 38 dental practitioners, 6 hygienists, 13 dental nurses, 11 public health dietitians, 8 general medical practitioners, 51 specialist and general nurses, 9 pharmacists and 175 lay community members. The respondents were
Please answer all questions

1. If I want to stop my teeth decaying, it is more important to cut down how much sugar I eat/ drink, than to cut down how often I have it.

True/False/Don't know

2. If a drink says 'no added sugar' on the packaging, this means that it has no sugar in it, and that it is safe for my teeth.

True/False/Don't know

3. I should rinse out my mouth after brushing to remove all the toothpaste.

True/False/Don't know

4. All children should use a children's toothpaste with less fluoride in it than in an adult toothpaste.

True/False/Don't know

5. Mouthwashes are just as effective as flossing at preventing gum disease.

True/False/Don't know

6. If I brush my teeth for 3-5 minutes twice a day I won't get any tooth decay.

True/False/Don't know

7. If my gums bleed, I should avoid brushing and flossing in these areas.

True/False/Don't know

8. Brushing my teeth straight after drinking a fizzy drink will protect them.

True/False/Don't know

9. When brushing my teeth, it is more important to brush the teeth themselves than around the gums.

True/False/Don't know

Many thanks for taking part!

Fig. 1 Risk factor questions for the prevention of dental disease

separated into three categories for analysis, one dental professional group comprising 61 participants, one professional health care group comprising 79 participants and one lay community group of 175 participants. All participants answered all nine questions. However, some practices in each group did not engage with the researcher when invited to do so. There is no record of numbers of individuals refusing to engage.

Within the dental group 20 (32.8\%) were male. Ten $(12.7 \%)$ males were in the healthcare group and $73(41.7 \%)$ in the general public group.

Age-ranges for the three groups are shown in Table 1.

\section{Oral health knowledge}

Thirty-five (57.4\%) of the dental group answered the whole questionnaire correctly, identifying that all nine statements were false. One incorrect (wrong or don't know) answer was given by 23 (37.7\%) individuals, two incorrect answers were given by two individuals and three incorrect answers by one individual. 


\begin{tabular}{|c|c|c|c|c|}
\hline & Dental & Healthcare & Lay community & Total \\
\hline $20-25$ & $8(13.1)$ & $3(3.8)$ & $34(19.4)$ & $45(14.3)$ \\
\hline $26-30$ & $11(18)$ & $14(17.7)$ & $13(7.4)$ & $38(12.1)$ \\
\hline $31-40$ & $18(29.5)$ & 26 (32.9) & 48 (27.4) & $92(29.2)$ \\
\hline $41-50$ & $12(19.7)$ & $27(34.2)$ & $39(22.3)$ & $78(24.8)$ \\
\hline $51-60$ & $11(18)$ & $8(10.1)$ & 29 (16.6) & $48(15.2)$ \\
\hline $60+$ & $1(1.6)$ & $1(1.3)$ & $12(6.9)$ & $14(4.4)$ \\
\hline Total & $61(100)$ & $79(100)$ & 175 (100) & \\
\hline
\end{tabular}

Table 2 Responses to questions categorised by topic by each group
\begin{tabular}{l|l|l|l|l|l|l|l|}
\hline Dental & \multicolumn{2}{l}{ Answers (no. and \%) } \\
\cline { 2 - 9 } Topic & Correct & \multicolumn{2}{l|}{ Wrong } & Don't know \\
\hline Caries $(n=244)$ & 217 & 88.93 & 23 & 9.43 & 4 & 1.64 \\
\hline Periodontal $(n=244)$ & 243 & 99.59 & 1 & 0.41 & 0 & 0.00 \\
\hline Erosion $(n=61)$ & 59 & 96.72 & 2 & 3.28 & 0 & 0.00 \\
\hline
\end{tabular}

\begin{tabular}{|c|c|c|c|c|c|c|}
\hline \multicolumn{7}{|l|}{ Healthcare } \\
\hline \multirow{3}{*}{$\begin{array}{l}\text { Topic } \\
\text { Caries }(n=316)\end{array}$} & \multicolumn{6}{|c|}{ Answers (no. and \%) } \\
\hline & \multicolumn{2}{|c|}{ Correct } & \multicolumn{2}{|c|}{ Wrong } & \multicolumn{2}{|c|}{ Don't know } \\
\hline & 236 & 74.68 & 66 & 20.89 & 14 & 4.43 \\
\hline Periodontal $(n=316)$ & 289 & 91.46 & 10 & 3.16 & 17 & 5.38 \\
\hline Erosion $(n=79)$ & 51 & 64.56 & 21 & 26.58 & 7 & 8.86 \\
\hline \multicolumn{7}{|c|}{ Community lay members } \\
\hline \multirow{2}{*}{ Topic } & \multicolumn{6}{|c|}{ Answers (no. and \%) } \\
\hline & \multicolumn{2}{|c|}{ Correct } & \multicolumn{2}{|c|}{ Wrong } & \multicolumn{2}{|c|}{ Don't know } \\
\hline Caries $(n=700)$ & 305 & 43.57 & 322 & 46.00 & 73 & 10.43 \\
\hline Periodontal $(n=700)$ & 543 & 77.57 & 88 & 12.57 & 69 & 9.86 \\
\hline Erosion $(n=175)$ & 93 & 53.14 & 59 & 33.71 & 23 & 13.14 \\
\hline
\end{tabular}

For the professional healthcare group $22(27.8 \%)$ answered the questionnaire correctly, with 22 (27.8\%) individuals having only one incorrect answer and 35 (44.3\%) having more than two incorrect answers.

The lay community group had nine (5.1\%) individuals answer the questionnaire correctly, with 12 (6.8\%) individuals having only one incorrect answer and 154 (88.1\%) having more than two incorrect answers.

The difference in oral health knowledge between the dental group and healthcare group was significant (chi-square $\mathrm{p}<0.001$ ) when analysed by number of totally correct questionnaires. Also the healthcare group showed a significant difference from the lay community group (chi-square $\mathrm{p}<0.0001$ ).

Table 2 lists the responses to questions categorised by topic by each group and Figure 2 shows graphically how the percentage of 'incorrect answers' for the three groups compare.

\section{Caries, periodontal disease and erosion}

The number of correct answers for caries compared with periodontal disease were significantly different (chi-square $\mathrm{p}<0.0001$ ) for all three groups, with a better knowledge of risk factors for periodontal disease than caries for all three groups; dental, health carers and lay community.

When comparing knowledge of risk factors for erosion with periodontal disease and caries in the three groups, the dental group showed no significant differences for both erosion and caries and also erosion and periodontal disease. The professional healthcare group also showed no significant difference for erosion and caries, however, a significant difference was found between erosion and periodontal disease (chi-square $\mathrm{p}<0.0001$ ). The lay community group showed a significant difference for both erosion and

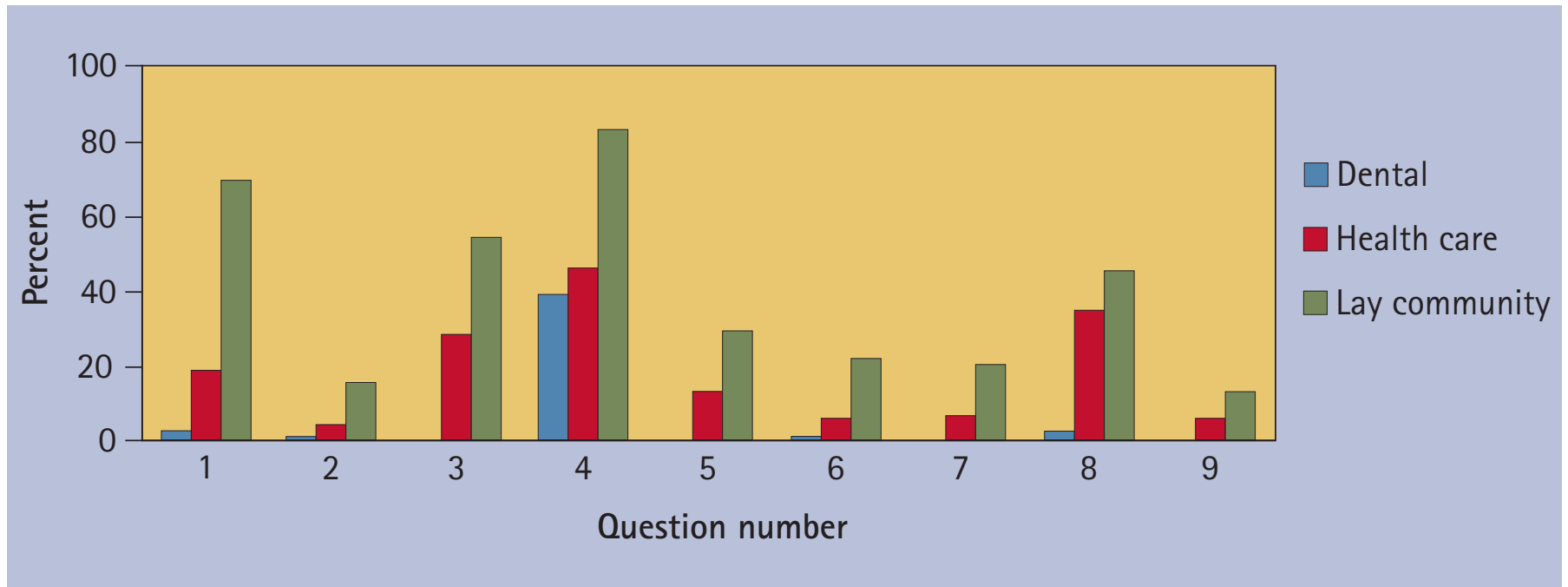

Fig. 2 Questions as answered incorrectly (wrong or 'don't know') by the three groups 
periodontal disease (chi-square $\mathrm{p}<0.0001$ ) and erosion and caries (chi-square $\mathrm{p}<0.05$ ).

From the lay members perspective questions one, three and four were the questions answered incorrectly most often. Question four, regarding the concentration of fluoride toothpastes for children, was answered incorrectly by 146 (83\%) individuals, making it the question that was answered incorrectly most often by lay community. This was followed by question one, regarding the frequency versus amount of sugar intake, answered incorrectly by 139 individuals (70\%); and question three, regarding rinsing after brushing, answered incorrectly by 96 individuals (55\%). Similar proportions are observed in healthcare and dental groups although of different magnitude. All these questions are associated with caries.

Question eight, regarding erosion, ranked next in the number of incorrectly answered responses by lay community, 80 individuals (46\%).

\section{Effect of professional experience and attendance patterns}

There was no significant difference between the number of correct answers given by the dental group when analysed by years of professional experience and the same applied to the healthcare group. For the lay community members, attendance patterns at the dentist did significantly affect the number of correct answers when grouped at those attending at least every 6 months and at least every 12 month (chi-square $\mathrm{p}<0.003$ and $\mathrm{p}<0.005$ respectively).

\section{DISCUSSION}

As expected, the dental professionals had better knowledge of the risk factors for dental disease prevention with 57\% answering all the questions correctly. However, it could be argued that a $100 \%$ correct response rate is expected from this group. It is interesting that the one question that appeared to be a problem for dental professionals is the question regarding fluoride levels in toothpastes for children. This can be explained by the fact that fluorosis as a result of excess fluoride use in infancy is a contentious issue. Fluoride toothpastes reduce dental decay by $24 \%$ on average compared with non-fluoride products. ${ }^{33}$ From a public health point of view, the risk of tooth decay and its consequences such as pain and extractions is greater than the small risk of fluorosis. This is particularly so for children considered to be at a high risk of tooth decay by their dentist. Toothpastes with fluoride concentrations less than 1,000 ppm are only as effective as non-fluoride toothpastes at preventing tooth decay. ${ }^{34}$ Evidence-based guidelines have been developed by the Department of Health and the British Association for the Study of Community Dentistry (BASCD) advising the use of toothpastes with adequate fluoride concentrations. ${ }^{35}$ Therefore, it is not surprising that this question was answered incorrectly most often by both the health caregroup and also lay community members. This also questions the efficacy of the methods adopted by the Department of Health in publishing and distributing guidelines.

Furthermore, as expected, there were knowledge gaps between the three groups. For all groups it seems that the knowledge on risk factors for periodontal health is better than that for caries prevention. The main issue contributing to the significant difference is the use of fluoride toothpastes in children. This was followed by an understanding of the frequency of intake of sugars and finally rinsing behaviours following tooth brushing. The three issues could be addressed within the realm of oral health promotion. In doing so, there are no cost implications for the first two issues. Simply modifying what patients are doing by substituting a toothpaste of adequate strength and not rinsing following brushing is all that is needed for those that are brushing. The other issue requires clear communication of the need for adequate re-mineralisation of enamel and this is the challenge for dental and health carers. Stillman-Lowe stressed the importance of accurate messages and messages that are unambiguous if an impact is to be made on oral health improvement. ${ }^{27}$ Richards and Filipponi discussed the ambiguity of oral health education messages and safe snacks. ${ }^{36}$

Periodontal health has improved over the period 1998 to 2009, with 17\% of the adult population having very good periodontal health. ${ }^{37,38}$ It could be that oral health education has been relatively successful here in understanding the need for good plaque control. Further improvements in periodontal health may need a focus on effectiveness of personal actions rather than knowledge. This study seems to support the findings of the Adult Oral Health Surveys. Improving compliance with regard to plaque control and other risk factors may benefit from the application of health behaviour change principles in general dental practice. ${ }^{39,40}$

It is interesting that the health care group showed a significant difference between the knowledge of periodontal disease and erosion but not between caries and erosion. The relatively good knowledge base surrounding periodontal disease manifested as a significant difference from the relatively poor knowledge base regarding erosion. The poor knowledge bases for both erosion and caries showed no significant difference. Could this reflect a confusion surrounding the biological acid attack associated with frequent sugar intake and the direct acid attack following acidic food/drink intake? This is an issue for improved OHE with educators (including healthcare workers), as a better understanding of the aetiology of the diseases is needed.

The prevention and reduction of dental diseases namely caries, periodontal disease and erosion could be considered a 'simpler' task in relation to behaviour change approaches in comparison with the challenges of other conditions such as diabetes type 2, cardiovascular diseases and obesity. ${ }^{41}$ Many younger cohorts of children are not experiencing dental caries as a result of effective prevention. ${ }^{42}$ However, epidemiological surveys show that caries are still a burden on society but the distribution of disease is skewed in populations. The populations with high levels of dental caries are generally but not exclusively deprived populations. ${ }^{43}$ Dental diseases, especially dental caries, are the most expensive to treat in terms of direct cost with $4-11 \%$ of European countries' health budgets spent on dental care. ${ }^{44}$ Efforts to fund preventive schemes are therefore welcome initiatives. ${ }^{45,46}$ In order to be most cost and outcome effective a consistent macro, meso and micro oral health promoting approach is required. ${ }^{47}$ This includes consistent, accurate and unambiguous messages at all levels. ${ }^{27}$ If as health promoters we are not able to improve/reduce inequalities in oral health how can we expect to influence the epidemic of other chronic conditions?

In the context of consistent messages the food industry has a part to play in the production, distribution and advertising of its products. Dental health product manufacturers also have a responsibility in production, distribution and advertising of products. Clearly, both the food and dental health product industries have to satisfy their business interests and generate profits. With that in mind, business interests and health interests are not mutually exclusive, for example, the literature produced by the sugar industry has a sound theoretical basis (demineralisation and remineralisation of enamel) for promoting oral health, although it could be argued that there is a business interest bias. ${ }^{48}$ Moreover, the addition of fluorides to toothpastes has had a major impact on caries. The production of flavoured children's toothpastes containing adequate levels of fluoride will clearly make it easier for parents to encourage their use. 
English $^{49}$ and Welsh ${ }^{50}$ governments place the general dental practitioner at the heart of delivering services to the community in conjunction with other key healthcare workers. Capacity for NHS care has the potential to increase as a result of disease trends and also contemporary preventive practice including the application of caries diagnosis and management utilising minimal intervention techniques. This is particularly so if appropriate attendance for routine recall follows risk. The results of this survey suggest that there is a knowledge gap between and within groups that may hinder clinical effectiveness. The social gradient in disease experience associated with deprivation must not be seen as the status quo for future disease activity in individuals. Disease activity is the responsibility of the individual regardless of social standing and the focus clearly needs to be on the behaviours that are required of individuals. Wamal et al. identified that lifestyle factors explained only $29 \%$ of the socioeconomic differences in poor oral health among men and women, whereas lack of access to dental care services explained about $60 \%$ in their analysis of Swedish National Survey data. ${ }^{51}$ A National Survey of British adults showed that oral health compromising behaviours tend to cluster with each other and they do not occur in isolation, suggesting chances of having detrimental behavioural clustering are lower in more educated groups in population. ${ }^{52}$ There is an opportunity present for improved information transfer in order to influence the behaviours of the sub-groups with the most to gain.

\section{LIMITATIONS}

There are methodological issues that should be discussed. The psychometric qualities of the questionnaire have not been tested for validity and reliability.

The majority of health professionals who completed the questionnaire were attending further education courses at the University of South Wales. Health professionals engaged in continuing and further education are more likely to be interested in expanding their knowledge and to provide up-to-date evidence based recommendations. The same can be said for the community members as venues visited for data collection included: health and fitness classes held in leisure centres, cookery classes, slimming and healthy eating classes, drawing classes, held in 'Communities First' venues. People engaged in these activities could possibly be less isolated; more interested in their general health, physical and mental wellbeing. There are potential biases in that those who are more motivated and well informed completed the questionnaire.
Although the locations of the community groups were chosen from areas considered to be more deprived, whether a representative sample of deprived populations was achieved is not known. These biases, if present, further supports the findings of the study in that the knowledge base of these participants would be greater than a 'true' sample of the population.

No analysis was available for nonresponse/participants and this should be considered when the results of the study are interpreted.

\section{CONCLUSION}

The results of this survey demonstrate a knowledge gradient from dental professionals through to healthcare professionals and then to lay members of the community. The knowledge base observed in the dental group is reflected in the other two groups as would be expected, albeit with a significant gap between each group. As expected the dental professionals are generally, but not totally, well informed. The question of fluoride levels in children's toothpaste proved to be a contentious issue. This knowledge gap within the dental professionals suggests improved CPD is necessary in this area.

Behaviour change approaches can play an important role in the prevention and reduction of dental diseases provided the key messages are consistent, accurate and unambiguous.

1. Levine R S, Stillman-Lowe C R. The scientific basis of oral health education. London: BDJ Books, 2009.

2. Welsh Government Consultation Document. Together for health: a national oral health plan for Wales. Welsh Government, 2012.

3. Kelly M, Steele J, Nuttall N et al. Adult Dental Health Survey: oral health in the United Kingdom 1998. London: The Stationery Office, 2000.

4. The Health and Social Care Information Centre. Adult Dental Health Survey 2009. London: HSCIC, 2011.

5. British Dental Association. Oral health inequalities policy. London: BDA, 2009. Online policy available at http://www.bda.org/dentists/policy-campaigns/ public-health-science/public-health/oral-healthinequalities.aspx (accessed January 2014).

6. World Health Organization. Equity, social determinants and public health. Geneva: WHO, 2010.

7. Kay E J, Locker D. Effectiveness of oral health promotion: a review. London: Health Education Authority, 1997.

8. Schou L Wright C. Does dental health education affect inequalities in dental health? Community Dent Health 1994; 11: 97-100.

9. Sprod A J, Anderson A, Treasure E T. Effective oral health promotion: literature review. Technical report 20. Cardiff: Health Promotion Wales, 1996.

10. Threlfall A G, Hunt C, Milsom K, Tickle M, Blinkhorn A S. Exploring factors that influence general dental practitioners when providing advice to help prevent caries in children. Br Dent J 2007; 202: E10.

11. O'Mullane D, Whelton H. Caries prevalence in the Republic of Ireland. Int Dent J 1994; 44: 387-391.

12. Batchelor P. 'What do we mean by population health?' Community Dent Oral Epidemiol 2012; 40: 12-15.

13. Frencken J E, Peters M C, Manton D J, Leal S C, Gordan VV, Eden E. Minimal intervention dentistry for managing dental caries - a review report of a
FDI task group. Int Dent J 2012; 62: 223-243.

14. Hong C H, Bagramian R A, Hashim Nainar S M, Straffon L H, Shen L, Hsu C Y. High caries prevalence and risk factors among young preschool children in an urban community with water fluoridation. Int J Paediatr Dent 2013; DOI: 10.1111/ipd.12023.

15. López R, Fernández 0 , Baelum V. Social gradients in periodontal diseases among adolescents. Community Dent Oral Epidemiol 2006; 34: 184-196.

16. Borrell L N, Burt B A, Neighbors H W, Taylor G W. Social factors and periodontitis in an older population. Am J Public Health 2004; 94: 748-754.

17. Borrell L N, Taylor G W, Borgnakke W S et al. Factors influencing the effect of race on established periodontitis prevalence. J Public Health Dent 2003; 63: 20-29.

18. Milosevic A, Young P J, Lennon M A. The prevalence of tooth wear in 14-year-old school children in Liverpool. Community Dent Health 1994; 11: 86-86.

19. Al-Dlaigan Y H, Shaw L, Smith A. Dental erosion in a group of British 14-year-old, schoolchildren. Part I: prevalence and influence of differing socioeconomic backgrounds. Br Dent J 2001; 190: 145-149.

20. Patrick $H$, Nicklas T. A review of family determinants of children's eating patterns and diet quality. J Am Coll Nutr 2005; 24: 83-92

21. Williams D, Croucher R, Marcenes W, O'Farrell M. The prevalence of dental erosion in the maxillary incisors of 14-year-old schoolchildren living in Tower Hamlets and Hackney UK. Int Dent J 1999; 49: $211-216$

22. Van Rijkom H M, Truin G J, Frencken J E et al. Prevalence, distribution and background variables of smooth-bordered tooth wear in teenagers in The Hague, The Netherlands. Caries Res 2002; 36: 147-154.

23. Bardsley P F, Taylor S, Milosevic A. Epidemiological studies of tooth wear and dental erosion in 14-year-old children in North West England. Part 1: the relationship with water fluoridation and social deprivation. Br Dent J 2004; 197: 413-416.

24. Peres K G, Armênio M F, Peres M A, Traebert J, Lacerda J T. Dental erosion in 12-year-old schoolchildren: a cross-sectional study in Southern Brazil. Int J Paediatr Dent 2005; 15: 249-255.

25. El Karim I A, Sanhouri N M, Hashim N T, Ziada H M. Dental erosion among 12-14-year-oldschool children in Khartoum: a pilot study. Community Dent Health 2007; 24: 176-180.

26. Mangueira D F, Sampaio F C, Oliveira A F. Association between socioeconomic factors and dental erosion in Brazilian schoolchildren. J Public Health Dent 2009; 69: 254-259.

27. Shah $K$, Hunter M L, Fairchild R M, Morgan M Z. A comparison of the nutritional knowledge of dental, dietetic and nutritional students. Br Dent J 2011; 210: 33-38.

28. Threlfall A G, Milsom K M, Hunt C M, Tickle M, Blinkhorn A S. Exploring the content of the advice provided by general dental practitioners to prevent dental caries in young children. Br Dent J 2007; 202: E9.

29. Stillman-Lowe C. Oral health education: what lessons have we learned? Br Dent J 2008; Suppl 2: 9-13.

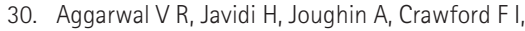
Sharif M O. Patients' knowledge of risk factors for dental disease. A pilot service evaluation in a general dental practice. Prim Dent Care 2010; 17: 173-177.

31. Welsh Government. Welsh Index of Multiple Deprivation. Summary report. Welsh Government 2011. Online information available at http:// wales.gov.uk/topics/statistics/publications/ wimd 11summary/?lang=en (accessed January 2014)

32. Ben-Shlomo, Y, Brookes, S, Hickman M. Epidemiology, evidence-based medicine and public health: lecture notes. Oxford: Wiley-Blackwell, 2013.

33. Marinho V C, Higgins J P, Logan S, Sheiham A. Fluoride toothpastes for preventing dental caries in children and adolescents (review). The Cochrane Library 2009; issue 1.

34. Conway D I, MacPherson L M, Stephen K W, Gilmou W H. Petersson L G. Prevalence of dental fluorosis in children from non-water-fluoridated Halmstad Sweden: fluoride toothpaste use in infancy. Acta Odontol Scand 2005; 63: 56-63. 
35. Department of Health and the British Association for the Study of Community Dentistry. Delivering better oral health: an evidence-based toolkit for prevention. London: Department of Health, 2007.

36. Richards W, Filipponi T. An effective oral health promoting message? Br Dent J 2011; 211: 511-516.

37. Adult Dental Health Survey Summary Report. Online report available at http://www.hscic.gov.uk/pubs/ dentalsurveyfullreport09 (accessed February 2014).

38. The Health and Social Care Information Centre Disease and related disorders - a report from the Adult Dental Health Survey 2009. London: HSCIC, 2011.

39. Ramsier C A, Survan J E. Health behaviour change in the dental practice. Wiley-Blackwell, 2010.

40. Richards W. Patient-centred dental practice: a behavioural approach. Dental Nursing 2012; 8: 443-447.

41. World Health Organization. Preventing chronic diseases: a vital investment. Geneva: WHO, 2005.
42. Childhood epidemiology programme. Online information available at http://www.cardiff.ac.uk/ dentl/research/themes/appliedclinicalresearch/ epidemiology/oralhealth/index.html (accessed February 2014).

43. Tickle M. The $80: 20$ phenomenon: help or hindrance to planning caries prevention programmes? Community Dent Health 2002; 19: 39-42.

44. Sheiham A. Dietary effects on dental disease. Public Health Nutr 2001; 4(2B): 569-591.

45. NHS Scotland. Child Smile programme. Online information available at www.child-smile.org (accessed January 2014).

46. Welsh Assembly Government. Designed to Smile programme. Online information available at http:// www.designedtosmile.co.uk/home.html (accessed January 2014).

47. Schou L, Blinkhorn A S (eds). Oral health promotion.
Oxford: Oxford University Press, 1993.

48. Sugar Nutrition UK. Researching the science of sugar. Online information available at www. sugarnutrition.org.uk (accessed January 2014).

49. Department of Health. Improving oral health with the new dental contract. London: DH, 2007.

50. Welsh Government. Delivery plan together for health: a national oral health plan for Wales 20132018 WG 17977. Welsh Government, 2013.

51. Wamala S, Merlo J, Boström G. Inequity in access to dental care explains socioeconomic disparities in oral health: the Swedish national surveys of public health 2004-2005. J Epidemiol Community Health 2006; 60: 1027-1033.

52. Singh A Rouxel P Watt R G Tsakos G. Social inequalities in clustering of oral health related behaviours in a national sample of British adults Prev Med 2013; 57: 102-106. 